\title{
Fitiríase palpebral
}

Camila Mota Neves*

\section{RESUMO}

A fitiríase palpebral é uma condição rara nas crianças. Os sintomas podem variar desde o prurido palpebral à blefarite com conjuntivite associada. O diagnóstico é feito com base na história clínica e com o exame físico, recorrendo a lupa ou lâmpada de fenda. $O$ tratamento pode ser difícil, prolongado e controverso. Apresentamos um breve caso de uma criança de 3 anos no qual houve um atraso no diagnóstico e onde o médico de família pôde desempenhar um papel essencial, tanto na avaliação do contexto dos contactos, como na interrupção do circuito de infestação.

Palavras-chave: Phtirus; Pestanas; Piolho; Pediculose.

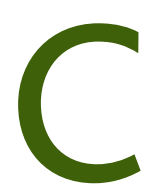

riança do sexo feminino, com 3 anos, sem antecedentes patológicos de relevo, pertencente a uma família nuclear, na fase III do ciclo de Duvall e da classe III de Graffar. O agregado é constituído por 4 elementos e apresenta um padrão adequado de procura de cuidados de saúde, comparecendo regularmente às consultas agendadas. A criança fica durante o dia num infantário. Apresentou-se na consulta com queixas de prurido e descamação palpebral («remelas») persistentes desde há seis meses, inicialmente no olho direito e um mês depois bilateralmente. Ao exame a olho nu apresentava ligeiro edema e rubor palpebral e algumas crostas nas pestanas junto aos bordos palpebrais. Foi tratada inicialmente na nossa consulta para uma blefarite com oxitetraciclina tópica, sem sucesso. Posteriormente, numa consulta de Pediatria da irmã, foi-lhe diagnosticada fitiríase palpebral, causada pelo insecto Phthirus pubis. Foi tratada com mousse à base de óleo de coco e anis (que actua como agente físico) em duas aplicações únicas separadas por 10 dias. Não voltou a apresentar sinais ou sintomas após o tratamento.

Nenhum dos progenitores apresentava qualquer tipo de sinais ou sintomas de infestação pelo insecto. A suspeita da origem da transmissão do Phthirus pubis recaiu sobre a educadora, que apresentava sinais semelhantes de fítiríase palpebral e que foi tratada com sucesso pelo seu médico assistente.

O Phthirus pubis, também conhecido como piolho

* Interna de Medicina Geral e Familiar UCSP Senhora da Hora - ACES Matosinhos púbico ou "chato", é um insecto hematófago e hospedeiro específico do ser humano. ${ }^{1}$ É transmitido geralmente através de contacto sexual, embora ocasionalmente também por roupas de uso pessoal, lençóis de cama e mesmo toalhas. Habita preferencialmente a região púbica, contudo pode aparecer em todo o corpo humano. ${ }^{2}$

As crianças podem ser atingidas por esta patologia, apesar de tal ser geralmente descrito como raro e não tendo sido encontrados dados sobre a prevalência e incidência da infestação neste grupo etário. Em crianças as pestanas são o local mais comummente afectado, devido não só às condições de humidade e temperatura, como também à ausência da maior parte dos pêlos terminais na pré-puberdade. ${ }^{3}$ Muitas vezes o contágio é feito por contacto com familiares ou cuidadores, sendo necessário despistar a possibilidade de abuso sexual. ${ }^{4}$

Os sintomas associados à fitiríase palpebral vão desde o prurido palpebral à blefarite com conjuntivite associada, podendo ocasionalmente haver linfadenopatias e infecção secundária. ${ }^{5}$ Podem existir ainda manchas azuis, designadas máculas cerúleas, devido à mordedura do Phthirus pubis nas margens da pálpebra. ${ }^{6}$

O diagnóstico é feito com base na história clínica e com a confirmação através da observação dos parasitas utilizando uma lupa ou microscópio (Figura 1 e 2). ${ }^{5}$

O tratamento pode ser difícil, prolongado e controverso, havendo diferentes terapêuticas defendidas, que vão desde a extracção mecânica à aplicação de meios físicos ou químicos. ${ }^{7}$ Alguns trabalhos referem a extracção mecânica directa como tratamento mais eficaz 


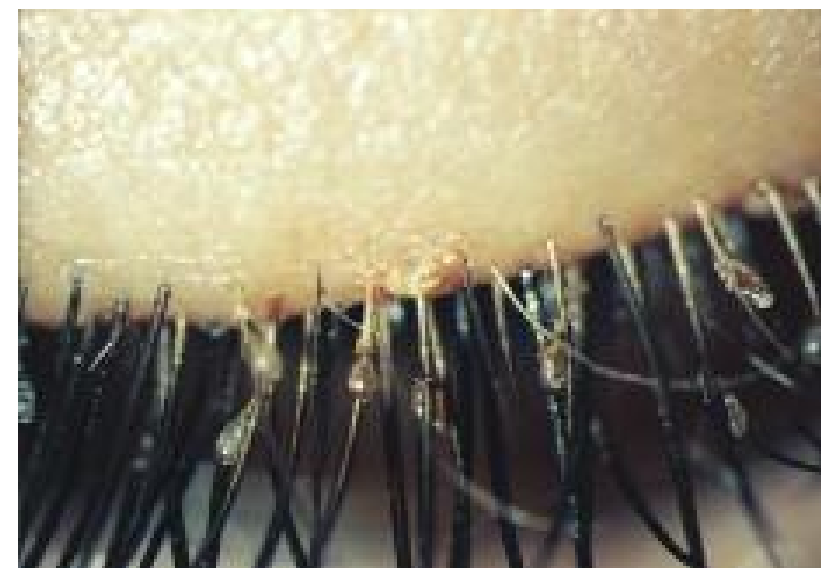

Figura 1.

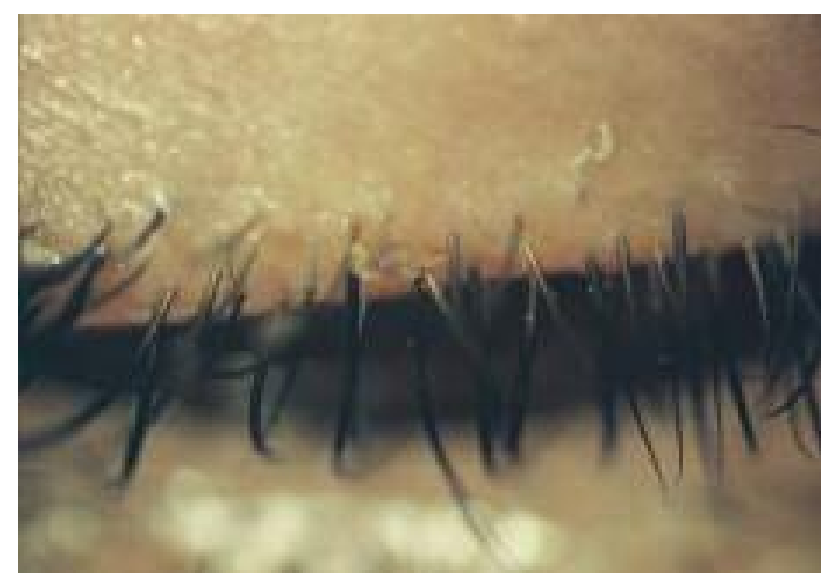

Figura 2.

e com menor risco, o que se mostra difícil em crianças não colaborantes. ${ }^{8}$ Como agente físico pode ser utilizada, por exemplo, a vaselina em pomada, que age como agente sufocante e ajuda na extracção dos parasitas. ${ }^{7}$ Existem vários agentes químicos pediculicidas, como por exemplo a permetrina ou a fluoresceína, contudo, a sua toxicidade limita o uso nesta localização. Para além disso, muitos dos químicos existentes não podem ser usados em crianças. ${ }^{9,10}$ Existem ainda outros tratamentos como crioterapia e fototerapia com árgon laser mas que são difíceis de aplicar nesta faixa etária. ${ }^{10}$ Devem ser tratados todos os grupos afectados. As roupas e objectos pessoais devem ser lavados a $50^{\circ}$ C durante 30 minutos. ${ }^{11}$ Em alternativa podem-se fechar os objectos e roupas pessoais num saco de plástico durante 2 semanas. ${ }^{11}$
Com a apresentação deste caso pretende-se sublinhar a sua dificuldade diagnóstica, por a fitiríase palpebral ser uma patologia rara em crianças e de difícil diagnóstico a olho nu. Alerta, assim, para a necessidade de, no exame físico subsequente a queixas e/ou sinais persistentes das pálpebras e pestanas, ser utilizada uma lupa (caso não esteja disponível uma lâmpada de fenda). De realçar, também, a importância de conhecer, quer localizações possíveis do parasita no corpo humano e formas de contágio, quer o contexto e os contactos da criança, de forma a compreender a origem da infestação, a detectar eventuais problemas associados (como as situações de abuso) e a agir de acordo com cada situação. Ilustra também a terapêutica mais adequada (agentes físicos) na idade em questão (3 anos), visto a extracção mecânica ser difícil, por não colaboração, e o uso de químicos pediculicidas ser contra-indicado pela sua toxicidade. O médico de família pode desempenhar um papel fundamental, tanto na avaliação diagnóstica, abordagem terapêutica inicial, referenciação aos cuidados de saúde secundários para optimização terapêutica, quando necessário, bem como avaliação dos contactos, incluindo a suspeição ou não de abusos, e interrupção do circuito de infestação.

Foram realizadas duas intervenções no infantário a partir do Centro de Saúde no sentido de informar sobre a problemática em questão e despistar outras fontes de contágio de forma a quebrar o ciclo de infestação. Foi também confirmada a suspeita da infestação da educadora e do seu tratamento adequado.

\section{AGRADECIMENTOS}

Agradeço ao Dr Joré Byron Vicente Dias Fernandes, médico colaborador da Clinica Oftalmológica do Hospital das Clínicas da Universidade de São Paulo, pela cedência de imagens do seu arquivo pessoal.

\section{REFERÊNCIAS BIBLIOGRÁFICAS}

1. Slonka GF. Life-cycle and biology of lice. J Sch Health 1977 Jun; 47 (6): 349-51.

2. Ubelaker JE, Payne E, Allison VF, Moore DV. Scanning electron microscopy of the human public louse, Phthirus pubis (Linnaeus, 1758). J Parasitol 1973 Oct; 59 (5): 913-9.

3. Burgess IF. Human lice and their management. Adv Parasitol 1995; 36 : 271-342.

4. Silburt BS, Parsons WL. Scalp infestation by Phthirus pubis in a 6-weekold infant. Pediatr Dermatol 1990 Sep; 7 (3): 205-7.

5. Couch JM, Green WR, Hirst LW, de La Cruz ZC. Diagnosing and treating Phthirus pubis palpebrarum. Surv Ophtalmol 1982 Jan-Feb; 26 (4): 219-25. 
6. Fitzpatrick's Dermatology in General Medicine. 4th ed. New York McGraw-Hill; 1993: 2819-21.

7. Charfi F, Ben Zina Z, Maazoun M, Kharrat W, Sellami D, Makni F, et al. Phthiriase ciliaire de l'enfant: diagnostic et traitement. J Fr Ophtalmol 2005 Sep; 28 (7): 765-8.

8. Schenone H. Eyelids infestación de los párpados de um niño por Phthirus pubis. Bol Chil Parasitol 2000 Ene-Jun; 55 (1-2): 25-6.

9. Blázquez Gamero D, Palacios Cuesta A, González-Tomé MI, Marín Ferrer M. Pedidulosis en las pestanas. An Pediatr (Barc). 2010 Feb; 72 (2): 145.

10. López García JS, García Lozano I, Martínez Garchitorena J. Phthiriasis palpebral: diagnóstico y tratamiento. Arch Soc Esp Oftalmol. 2003 Jul; 78 (7): 365-74.

11. Lin YC, Kao SC, Kau HC, Hsu WM, Tsai CC. Phthiriasis palpebralum: an unusual blepharoconjunctivitis. Zhonghua Yi Xue Za Zhi (Taipei), 2002 Oct; 65 (10): 498-500.

\section{CONFLITOS DE INTERESSE}

A autora declara não possuir conflitos de interesses.

\section{ENDEREÇO PARA CORRESPONDÊNCIA}

Camila Mota Neves

Rua da Lagoa

4460 Senhora da Hora

camilamotaneves@gmail.com

Recebido em 12/08/2011

Aceite para publicação em 24/11/2011

\section{ABSTRACT}

\section{PHTHIRIASIS PALPEBRARUM}

Phthiriasis palpebrarum is a rare condition in children. The symptoms associated with phthiriasis palpebrarum range from pruritic lid margins to blepharitis with marked conjunctival inflammation. The diagnosis is made based on clinical history and physical examination, using a magnifier or a slit lamp. Treatment is difficult, prolonged and controversial. We report a case of phthiriasis palpebrarum in a three-year-old female child in which there was some difficulty in the diagnosis. The general practitioner can play a key role in identifying contacts and in breaking the cycle of infestation.

Keywords: Phthirus, Eyelashes, Crab Louse, Pediculosis. 